\title{
Number of risk genotypes is a risk factor for major depressive
} disorder: a case control study

\author{
Holly A Garriock ${ }^{1,2}$, Pedro Delgado ${ }^{3}$, Mitchel A Kling ${ }^{4}$, Linda L Carpenter ${ }^{5}$, \\ Michael Burke ${ }^{6}$, William J Burke ${ }^{7}$, Thomas Schwartz ${ }^{8}$, Lauren B Marangell ${ }^{9}$, \\ Mustafa Husain ${ }^{10}$, Robert P Erickson ${ }^{1,11}$ and Francisco A Moreno*2
}

\begin{abstract}
Address: ${ }^{1}$ Interdisciplinary Program in Genetics, Department of Psychiatry, University of Arizona, Tucson, AZ, USA, ${ }^{2}$ Department of Psychiatry, College of Medicine, The University of Arizona Health Sciences Center, 1501 N. Campbell Ave. 7-OPC, Tucson, Arizona 85724, Phone (520) 6266509, Fax (520) 626-6050, USA, ${ }^{3}$ Department of Psychiatry, University of Texas Health Sciences Center at San Antonio, San Antonio, TX, USA, ${ }^{4}$ Neuroscience Center, National Institute of Mental Health, Rockville, MD, USA, ${ }^{5}$ Department of Psychiatry, Butler Hospital Brown University, Providence, RI, USA, ${ }^{6}$ Department of Psychiatry and Behavioral Sciences, Kansas University School of Medicine, Witchita, KS, USA, ${ }^{7}$ Department of Psychiatry, University of Nebraska Medical Center, Omaha, NE, USA, ${ }^{8}$ Department of Psychiatry, New York State School of Medicine, Purchase, NY, USA, ${ }^{9}$ Department of Psychiatry, Baylor College of Medicine, Waco, TX, USA, ${ }^{10}$ Department of Psychiatry, University of Texas Southwestern Medical Center, Dallas, TX, USA and ${ }^{11}$ Departments of Pediatrics and Molecular \& Cellular Biology, University of Arizona, Tucson, AZ, USA
\end{abstract}

Email: Holly A Garriock - habrown@email.arizona.edu; Pedro Delgado - delgadop@uthscsa.edu; Mitchel A Kling - klingm@mail.nih.gov; Linda L Carpenter - Linda_Carpenter_MD@Brown.EDU; Michael Burke - mjburke@kumc.edu; William J Burke - wjburke@unmc.edu; Thomas Schwartz - schwartzresearch1@yahoo.com; Lauren B Marangell - laurenm@bcm.tmc.edu; Mustafa Husain - Mustafa.Husain@utsouthwestern.edu; Robert P Erickson - Erickson@peds.arizona.edu; Francisco A Moreno* - fmoreno@email.arizona.edu

* Corresponding author

Published: 05 July 2006

Behavioral and Brain Functions 2006, 2:24 doi:10.1 186/1744-908I-2-24
Received: 10 April 2006

Accepted: 05 July 2006

This article is available from: http://www.behavioralandbrainfunctions.com/content/2/I/24

(C) 2006 Garriock et al; licensee BioMed Central Ltd.

This is an Open Access article distributed under the terms of the Creative Commons Attribution License (http://creativecommons.org/licenses/by/2.0), which permits unrestricted use, distribution, and reproduction in any medium, provided the original work is properly cited.

\begin{abstract}
Background: The objective of the study was to determine the genetic basis of Major Depressive Disorder, and the capacity to respond to antidepressant treatment. An association study of 21 candidate polymorphisms relevant to monoamine function and the mechanism of antidepressant response was conducted in 3 phenotypically distinct samples: a group with chronic or recurrent depression unable to respond to antidepressants (non-responders) $(n=58)$, a group capable of symptomatic improvement with or without treatment (responders) $(n=39)$, and volunteer controls $(n=85)$. The responders and non-responders constituted a larger group of depressed subjects.

Methods: A candidate gene approach was employed to asses the genetics basis of Major Depressive Disorder. The genotypic frequencies of selected polymorphisms were compared between the controls and depressed subjects. To asses the genetics basis of the capacity to respond to antidepressant treatment, the responders were compared to the non-responders. Candidate genes were chosen based on functional studies and proximity to whole genome linkage findings in the literature. Risk genotypes were identified by previous functional studies and association studies.

Results: A statistically significant difference in genotype frequency for the SLC6A4 intron 2 VNTR was detected between the subjects with a history of depression and controls $(p=0.004)$. Surprisingly, a statistically significant difference was detected between responders and nonresponders for the DRD4 exon III VNTR genotype frequencies $(p=0.009)$. Furthermore, a
\end{abstract}


difference between the controls and depressed subjects as well as between the controls and nonresponders was detected for the number and distribution of risk genotypes in each group.

Conclusion: An association between several monoamine-related genes and Major Depressive Disorder is supported. The data suggest that the two depressive phenotypes are genetically different, inferring that the genetic basis for the capacity to respond to standard antidepressant treatment, and the genetic susceptibility to Major Depressive Disorder may be independent. In addition, a proof of concept is provided demonstrating that the number of risk genotypes may be an indication of susceptibility of major depressive disorder and the severity of the disorder.

\section{Background}

Depression affects more than 40 million Americans at some time during their lives and represents one of the most debilitating medical conditions. A substantial body of evidence drawn from a range of methods, proband groups, and diagnostic criteria has established that a familial phenotype is present in patients with major depression [1-7]. Despite their limitations, molecular methods such as candidate gene association studies also support the concept of a genetic influence in vulnerability to depression $[8,9]$. Although genetic studies promise to improve our understanding of the pathophysiological and genetic aspects of the depressive syndrome, such understanding is limited by the genetic complexity and lack of discrete, etio-pathologically related, and homogeneous "depression" phenotypes.

Treatment resistant depression (TRD) is a characteristic of some depression phenotypes. It can range from not being able to respond to one medication, to not clinically responding to electroconvulsive therapy[10]. TRD, or non-response can be viewed as a spectrum of severity of major depressive disorder, as the amount of suffering is greater for those with TRD, than those without[11]. Whether or not TRD is a subtype of depression with a distinct underlying biology is still unknown and under investigation. It is possible that to some extent TRD is a result of hyperfunctioning enzymes that metabolize typical antidepressant medications [12]. In this case, the TRD subjects would have a genetic background that leads to a pharmacokinetic difference from the depressive group which is capable of antidepressant treatment response. This genetic discrepancy between two diagnostically similar groups (though phenotypically difference in terms of response profiles) may be detectable, and would provide insight to the biology of treatment resistant depression.

To explore genetic differences within depression endophenotypes, we genotyped Caucasian subjects with unipolar major depression from two distinct treatment response profiles: those able to respond to treatment, and those not able to respond. The genes being studied encode for receptors, transporters, synthetic or degradation enzymes, transcription factors, and neurotrophic factors related to monoamine function. We hypothesized that the depressive group as a whole would be genetically distinct from the healthy controls. It was predicted that there would be a higher frequency of "risk" genotypes (excessive or deficient in functioning depending on the case) in the depressive groups when compared to the controls.

We report one two single gene findings and one polygenic discovery. A difference in genotypic frequency between the controls and depressed subjects was detected in the serotonin transporter intron 2 VNTR polymorphism. A surprising difference was detected between the responder and non-responders in the dopamine D4 receptor exon III VNTR. Furthermore, we demonstrate that depressed subjects have more risk genotypes that non-depressed subjects, and that non-responders have the most risk genotypes of all our phenotypic groups analyzed.

\section{Methods Subjects}

Ninety-seven subjects, aged 18 to 85 years and diagnosed with unipolar major depression (DSM-IV)[13] participated in the study (see Table 1). Fifty-eight of these subjects had participated in a research trial for treatment resistant depression (TRD); selection criteria for this group included clinical diagnosis of chronic or recurrent depression and failure to achieve remission after at least two adequate antidepressant trials as documented by the Antidepressant Treatment History Form (ATHF) [14-20] These subjects are a subgroup of a vagal nerve stimulation (VNS) trial, and express a highly debilitating course of major depressive disorder, and nearly $90 \%$ failed to respond to selective serotonin re-uptake inhibitors (SSRIs). Further details about the subjects has been previously described[21]. Thirty-nine others were selected because they had recovered from a major depressive episode (diagnosed according to DSM-III-R criteria), facilitated by the capability to respond to standard antidepressant medication. The response to the antidepressant medication was indicated by a score of $\leq 14$ on the 25 item - Hamilton Depression Rating Scale[22]. The control group consisted of 85 volunteer students from the University of Arizona, who denied a personal history of mental illness based on the mood disorders section of the 
Table I: Clinical description and demographics of subjects groups

\begin{tabular}{|c|c|c|c|c|}
\hline Subject term & Descriptive clinical information & $\mathrm{N}$ & $\%$ female & Mean years of age (range) \\
\hline Depressed & Combination of Non-responders and responders (see below) & 97 & $66.7 \%$ & $46.7(24-72)$ \\
\hline $\begin{array}{l}\text { Non-responders } \\
\text { (treatment resistant } \\
\text { depression) }\end{array}$ & $\begin{array}{l}\text { Clinical diagnosis of chronic or recurrent depression and failure to } \\
\text { achieve remission after at least two adequate antidepressant trials as } \\
\text { documented by the Antidepressant Treatment History Form (ATHF). }\end{array}$ & 58 & $61 \%$ & $47.2(24-65)$ \\
\hline Responders & $\begin{array}{l}\text { Clinical diagnosis of major depressive disorder, and capability to } \\
\text { respond to standard antidepressant medication. }\end{array}$ & 39 & $75 \%$ & $46.1(25-72)$ \\
\hline Controls & $\begin{array}{l}\text { Subjects who denied a personal history of mental illness based on the } \\
\text { mood disorders section of the Structured Questionnaire Interview for } \\
\text { DSM-IV-R (SCID) questionnaire. }\end{array}$ & 85 & $64.3 \%$ & $23.1(18-68)$ \\
\hline
\end{tabular}

Structured Questionnaire Interview for DSM-IV-R (SCID) questionnaire[23]. All participants were of European descent.

\section{Genotyping}

The study was approved by each of the participating institutions. All subjects gave written informed consent for genotyping; samples for DNA analysis were obtained from whole blood or cheek cells. PCR-based genotyping was performed at the Laboratory of Molecular Psychiatry of The University of Arizona for 21 genetic polymorphisms. The details of the analyzed polymorphisms can be found in Table 2. Primer sequences, methodology details and allele description can be found in TABLE 1S provided as supplemental information (See additional file 1). Genotypic frequencies did not deviate from expected Hardy-Weinberg frequencies.

\section{Statistical analysis}

Initially, four comparisons were made: between subjects with a history of major depression vs. controls, nonresponders vs. controls, responders vs. controls, and nonresponders vs. responders. The data presented in this study is a result of a chi-square analysis was used to test for differences in the frequency of genotype polymorphisms between the depressive subjects and healthy controls as well as between the responders and non-responders. The remaining two comparisons (responders vs. controls, non-responders vs. controls) is available upon request. All significance tests (aside from QVALUE) were done with SPSS version 14. Genotypic frequency differences were analyzed by Chi-Square tests. False discovery rate analysis was used to control for multiple comparisons between groups and number of polymorphisms. The q-values[24] are reported with all $\mathrm{p}$ values $\leq 0.05$. A q-value is an indication of the percent of time a Type I error would be committed if a corresponding $\mathrm{p}$-value was considered as statistically significant. For example, we accepted a false discovery rate of $15 \%$, thus based on the value distribution of the present dataset, a value of $\mathrm{q} \leq 0.137$ was considered statistically significant, however, this still implies that $13.7 \%$ of the time when we accept a corresponding p- value as statistically significant, an error would be made. The statistical testing for each polymorphism was between a risk genotype determined a priori to testing (see Table 2), and the remaining genotypic groups. The mean number of risk genotypes among the phenotypic groups was analyzed using independent samples t-tests. We chose this approach because we had hypotheses that the history positive group would have more risk genotypes that the history negative, and likewise, that the non-responders would have more risk genotypes that the non-responders.

\section{Results}

Table 3 provides the $\mathrm{p}$-value, and corresponding Q-value, for all the polymorphisms tested. A multiple comparison correction (Q-value) was used to decrease the number of false discoveries in the analysis. Genotype frequency differences were statistically significant for the serotonin transporter gene intron-2 VNTR (STin2) between subjects with a history of depression and controls $(\mathrm{p}=0.004)$. The disparate genotypic distribution exists in the heterozygote and 12-repeat homozygote groups. Over $50 \%$ of the controls fall into the 12/12 genotypic group, whereas just less than $30 \%$ of the depressed individuals do. Likewise, over half of the depressed subjects fall in the heterozygote group, whereas just over $30 \%$ of the controls do. The comparison between the depressed and non-depressed subjects also revealed that the DRD3 and two COMT polymorphisms were close to being statistically significant but did not hold up to multiple comparison correction. A statistically significant difference was detected in the genotypic frequency distributions between the nonresponders and the responders of the DRD4 exon 3 VNTR $(\mathrm{p}=0.009)$. The genotypic group with zero-7-repeat alleles was largely over-represented in the non-responders, compared to $38 \%$ of the responders. Likewise, the homozygous 7-repeat genotypic group had twice the amount of responders compared to non-responders.

Figure 1 shows the distribution of the number of risk genotypes for all phenotypic groups. The mean number of risk genotypes (see Figure 1) is statistically significantly different between the controls and depressed subjects $(\mathrm{p}=$ 
Table 2: Polymorphism Descriptions

\begin{tabular}{|c|c|c|c|c|c|}
\hline Gene Name & Risk Genotype & Gene function & $\begin{array}{l}\text { Type of } \\
\text { Polymorphism }\end{array}$ & $\begin{array}{l}\text { Chromosom } \\
\text { e Location }\end{array}$ & location in gene; details \\
\hline TFAP2B & ss/sl & transcription factor & $(\mathrm{CAAA})_{5-6}$ & $6 p \mid 2-p 21.1$ & $\begin{array}{l}\text { intron } 2 \text { near 3' splice site of exon 2; } \\
\text { SLC6A4, HTR2A, DbH, DRDI, SLC6A3 } \\
\text { have Ap2B binding sites }\end{array}$ \\
\hline BDNF & AA & Neurotrophic factor & $\begin{array}{l}\text { G-->A SNP at } \\
\text { nucleotide 196; } \\
\text { rs6265; }\end{array}$ & ||$p \mid 3$ & proBDNF coding region; (val66met) \\
\hline SLC6A4_IN/DEL & II & Serotonin transporter & $\begin{array}{l}44 \text { bp in/del (5- } \\
\text { HTTLPR) }\end{array}$ & $|7 q| 1 .|-q| 2$ & Promoter; actually a VNTR (xs-xl) \\
\hline SLC6A4_VNTR & $10 / 12$ & Serotonin transporter & $\begin{array}{l}\text { VNTR of } 17 \text { bp } \\
\text { element ( } 9-12 \text { copies) }\end{array}$ & $|7 q| 1 .|-q| 2$ & intron 2 \\
\hline DRD4_IN/DEL & sl/ss & $\begin{array}{l}\text { Dopamine receptor } \\
\text { D4 }\end{array}$ & I 20 bp in/del & IIpI5.5 & 5'-UTR \\
\hline DRD4_VNTR & 0 or I $7 R$ & $\begin{array}{l}\text { Dopamine receptor } \\
\text { D4 }\end{array}$ & 48 bp VNTR & IIpI5.5 & exon 3 \\
\hline HTR2A & $\mathrm{CC} / \mathrm{CT}$ & $\begin{array}{l}\text { Serotonin post- } \\
\text { synaptic receptor } 2 \mathrm{~A}\end{array}$ & CI02T SNP; rs63I3 & $|3 q| 4-q 2 \mid$ & exon I \\
\hline SLC6A3 & $9 / 9$ and $9 / 10$ & $\begin{array}{l}\text { Dopamine } \\
\text { transporter (SLC6A3) }\end{array}$ & $\begin{array}{l}40 \text { bp VNTR ( } 9 \text { and } 10 \\
\text { repeats most } \\
\text { frequent, but } 3-11 \\
\text { copies possible) }\end{array}$ & $5 p \mid 5.3$ & 3' non-coding region of exon 15 \\
\hline rs 165599 COMT & GG & $\begin{array}{l}\text { CATECHOL-O- } \\
\text { METHYLTRANSFERA } \\
\text { SE }\end{array}$ & $\begin{array}{l}\text { G-->A SNP (Mspl); } \\
\text { rsl65599 }\end{array}$ & $22 q 11.2$ & 3'-UTR; maybe in mRNA \\
\hline DRD3 & GG & $\begin{array}{l}\text { Dopamine receptor } \\
\text { D3 }\end{array}$ & $\begin{array}{l}\text { G-->A SNP (Glycine-- } \\
\text { > serine) (Mscl, } \\
\text { isoschizomer of Ball) } \\
\text { rs6280 }\end{array}$ & $3 q 13.3$ & $\begin{array}{l}\text { exon I (N-terminal extracellular } \\
\text { domain) }\end{array}$ \\
\hline DRD I & GG & $\begin{array}{l}\text { Dopamine Recptor } \\
\text { DI }\end{array}$ & G-->C SNP (Haelll) & $5 q 35.1$ & $-|25|$ \\
\hline DRD I & $\mathrm{CC}$ & $\begin{array}{l}\text { Dopamine Recptor } \\
\text { DI }\end{array}$ & $\begin{array}{l}\text { T-->C SNP } \\
\text { (Bsp|286I) }\end{array}$ & $5 q 35.1$ & 1403 \\
\hline DRDI & TT & $\begin{array}{l}\text { Dopamine Recptor } \\
\text { DI }\end{array}$ & T-->C SNP (HaellI) & $5 q 35.1$ & -800 \\
\hline HTR6 & $\mathrm{CC}$ & $\begin{array}{l}\text { Serotonin receptor } \\
6 \mathrm{~A}\end{array}$ & $\begin{array}{l}\text { T267C SNP (Rsal) } \\
\text { Tyr(89) silent } \\
\text { mutation; rs } 1805054\end{array}$ & $1 p 36-p 35$ & coding region (Ist extracellular loop) \\
\hline DRD I & GG & $\begin{array}{l}\text { Dopamine Recptor } \\
\text { DI }\end{array}$ & G-->A SNP (Ddel) & $5 q 35.1$ & -48 \\
\hline re4680 COMT & GG & $\begin{array}{l}\text { CATECHOL-O- } \\
\text { METHYLTRANSFERA } \\
\text { SE }\end{array}$ & $\begin{array}{l}\text { G-->A SNP } \\
\text { (val58met) (Nlalll) } \\
\text { rs } 4680\end{array}$ & $22 q 11.2$ & 4th exon (codon 158 or 108 ) \\
\hline MAOA & $\geq 3.6 \mathrm{R}$ combinations & $\begin{array}{l}\text { Monoamine Oxidase } \\
\text { type A }\end{array}$ & $\begin{array}{l}30 \text { bp VNTR ( } 2 R, 3 R \\
3.6 R, 4 R, 5 R, 7 R)\end{array}$ & $X p \mid I .23$ & $\begin{array}{l}\text { I. } 2 \mathrm{~kb} \text { upstream of coding region; } \\
\text { promoter }\end{array}$ \\
\hline HTRIA & GG/CG & $\begin{array}{l}\text { Serotonin Receptor } \\
\text { IA }\end{array}$ & $\begin{array}{l}\text { C-->G SNP (BstF5I) at } \\
\text { position - } 1019 \text { from } \\
\text { ATG start site }\end{array}$ & $5 q \mid 1.2-q 13$ & $\begin{array}{l}\text { PCR fragment is from }-1158 \text { to }-996 \\
\text { from ATG start site strobel, } 2003 ; \\
\text { promoter }\end{array}$ \\
\hline DBH & TT (AI/AI) & $\begin{array}{l}\text { Dopamine-beta- } \\
\text { hydroxylase }\end{array}$ & $\begin{array}{l}\text { C-->T SNp at position } \\
\text { I604; R535C (BstUl); } \\
\text { rs627I }\end{array}$ & $9 q 34$ & $\begin{array}{l}\text { exon II: I } 42 \text { bp fragment (originally } \\
\text { FnuDII digest). AI: } 95,47 \text { bp; A2: } 66,47 \text {, } \\
29 \text { bp. }\end{array}$ \\
\hline $\mathrm{TPH} 2$ & GG & $\begin{array}{l}\text { Tryptophan } \\
\text { Hydroxylase 2 } \\
\text { (neuronal TPH) }\end{array}$ & A-->G; rsI386494 & $12 q 21.1$ & intron 5 \\
\hline $\mathrm{TH}$ & 0,1 & Tyrosine Hydroxylase & VNTR & IIpI5.5 & \\
\hline
\end{tabular}


Table 3: P and Q-values for trending and statistically significant (after multiple comparison correction *) polymorphisms

\begin{tabular}{|c|c|c|c|c|}
\hline \multirow[b]{2}{*}{ Polymorphism } & \multicolumn{2}{|c|}{ Depressed vs. non-depressed } & \multicolumn{2}{|c|}{ Responders vs. non-responders } \\
\hline & $\mathrm{p}$-value & q-value & $\mathrm{P}$-value & q-value \\
\hline rs6280 DRD3 & 0.055 & 0.264 & 0.439 & 0.555 \\
\hline rs4680 COMT & 0.033 & 0.239 & 0.986 & 0.77 \\
\hline rs 165599 COMT & 0.041 & 0.239 & 0.251 & 0.482 \\
\hline STin2 VNTR SLC6A4 & $0.004 *$ & 0.137 & 0.749 & 0.699 \\
\hline exon 3 VNTR DRD4 & 0.316 & 0.482 & $0.009 *$ & 0.137 \\
\hline
\end{tabular}

$0.017)$ as well as between controls and non-responders ( $\mathrm{p}$ $=0.005)$.

\section{Discussion}

The genetic susceptibility to major depression was tested using genotype frequency comparisons between subjects with a history of depression and controls. We detected three polymorphisms (SLC6A4 intron 2 VNTR, 2 COMT polymorphisms) which may contribute to the genetic susceptibility to major depression, however, only one (SLC6A4) which held up to multiple comparison corrections.

The comparison between the non-responders and responders is a method to detect the genetic basis for antidepressant response, in general. Out of the 21 polymorphisms tested, only one (DRD4 exon 3 VNTR) was statistically significant. This is compared to the 3-4 polymorphisms which demonstrate a genetic susceptibility to depression. It was unpredicted that the genetic basis for antidepressant response may differ from the genetic basis of susceptibility to major depression.

We further demonstrated that the number of risk genotypes is not consistent across phenotypes. The non-

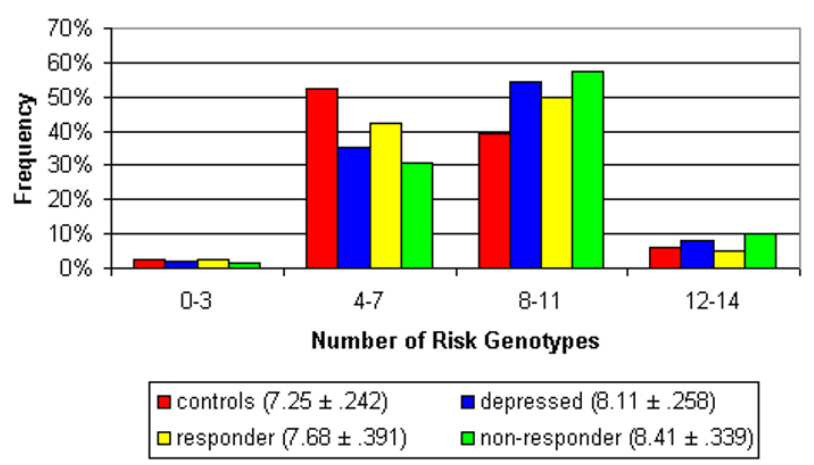

Figure I

Distribution of risk genotypes for all phenotypic groups (mean \# risk genotypes \pm SEM). responders have the most risk genotypes, followed by (in decreasing order) the depressed group as a whole, the responders, and the controls. This supports the notion that Major Depressive Disorder is polygenic, and that the number of risk genotypes may be an indication of the susceptibility to Major Depressive Disorder as well as the severity of the disorder.

In retrospect, we recognize that much of our current understanding of the pathophysiology of depressive disorders has been inferred from the prevailing hypotheses of mechanisms for antidepressant action. Accordingly, candidate genes selected for their function are commonly associated with monoamine function or their putative intracellular responses to neurotransmitter activation. The neurobiology of treatment resistance is not well understood; it may represent an extreme phenotype along a unique pathological continuum of depression. This interpretation may be supported by the fact that the usual monoamine-based treatment interventions, by definition, provide little or no benefit to patients with treatment resistant depression.

The Hamilton Depression Rating Scale has been for decades the gold standard of depression symptoms quantification and has been utilized in $>95 \%$ of antidepressant treatment studies. There have been lately a number of concerns primarily about the scale's ability to reliably quantify antidepressant responses given the multi-dimensionality of the scale, which may non-specifically determine response in individuals treated with sedating agents such as TCA's. In the other hand, given the number of non-melancholic specific items, it may be less sensitive at detecting an antidepressant response. It is possible that alternative tools such as the Bech Rafelsen or the Montgomery Asberg Depression Rating Scale among others may more accurately reflect antidepressant responses leading to a more reliable detection of therapeutic effects.

This pilot study provides a proof of concept that two depressive phenotypes (antidepressant response and nonresponse) may be subtypes of Major Depressive Disorder. In terms of medication response, these patients are clearly 
Table 4: Genotype frequencies for polymorphisms in Table 3 for all phenotypic groups. Risk genotype indiciated by an *.

\begin{tabular}{|c|c|c|c|}
\hline rs6280 DRD3 & AA & AG & GG* \\
\hline controls & $46(.55)$ & $34(.4 I)$ & $3(.04)$ \\
\hline depressed & $47(.50)$ & $34(.36)$ & $14(.14)$ \\
\hline responder & $18(.47)$ & $12(.32)$ & $8(.2 \mathrm{I})$ \\
\hline non-responder & $29(.5 I)$ & $22(.39)$ & $6(.10)$ \\
\hline rs4680 COMT & AA & AG & GG* \\
\hline controls & $26(.31)$ & $43(.52)$ & $14(.17)$ \\
\hline depressed & $30(.32)$ & $34(.36)$ & $30(.32)$ \\
\hline responder & $12(.32)$ & $13(.35)$ & $12(.32)$ \\
\hline non-responder & $18(.31)$ & $21(.37)$ & $18(.31)$ \\
\hline rsI65599 COMT & AA & AG & GG* \\
\hline controls & $46(.56)$ & $30(.37)$ & $6(.07)$ \\
\hline depressed & $40(.43)$ & $34(.37)$ & $18(.20)$ \\
\hline responder & $13(.35)$ & $14(.38)$ & $10(.27)$ \\
\hline non-responder & $27(.49)$ & $20(.36)$ & $8(.15)$ \\
\hline STin2 VNTR SLC6A4 & $10 / 10$ & $10 / 12 *$ & $12 / 12$ \\
\hline controls & $15(.18)$ & $25(.31)$ & $42(.51)$ \\
\hline depressed & $18(.19)$ & $49(.52)$ & $27(.29)$ \\
\hline responder & $8(.21)$ & $18(.47)$ & $12(.32)$ \\
\hline non-responder & $10(.18)$ & $31(.55)$ & $15(.27)$ \\
\hline Exon 3 VNTR DRD4 & $0-7 \mathbf{R}^{*}$ & I-7R* & $2-7 R$ \\
\hline controls & $56(67)$ & $22(.26)$ & $6(.07)$ \\
\hline depressed & $55(.57)$ & $36(.38)$ & $5(.05)$ \\
\hline responder & $15(.38)$ & $21(.54)$ & $3(.08)$ \\
\hline non-responder & $40(.70)$ & $15(.26)$ & $2(.04)$ \\
\hline
\end{tabular}

distinct from each other, thus it is logical to propose their genetic constitution may be distinct. The polymorphisms analyzed in this study is by no means an exhaustive list of polymorphisms which play a role in Major Depressive Disorder, however it is a fairly representative list for the monoamine related polymorphisms thought to confer susceptibility to major depression. It is true that the mean age of the controls is younger compared to the depressed groups, thus they have not necessarily passed the age of onset typical of major depressive disorder. As a result, we may be committing a type I error in the analyses, and be missing or underestimating genetic differences that exist between the controls and depressed subjects, however, we are confident in the effect that we did detect. A large number of comparisons between groups for each polymorphism were initially performed in this study. To correct for false discovery, a q-value was determined, which provided an indication of statistical significance. We accepted a q-value less than 15\%, which indicates that $15 \%$ of the time we considered out findings to be signifi- cant, we would be incorrect. Given that this is a pilot study with relatively small sample size, our single-polymorphism findings may be false positives, and thus necessitate replication in an independent and larger sample. Polymorphisms in alternative neurotransmitter systems, neurotrophic pathways, neurosteroids and antidepressant metabolic pathways (e.g. cytochrome p450 factors) should be the focus of further research.

\section{Conclusion}

Despite the modest sample size, these data support the existence of a genetic basis to the susceptibility to major depression. Furthermore, depending on the phenotypic definition used in testing, different associations may be detected. Given that we utilized phenotypic definitions based on patters of treatment response, these findings further suggest that the genetic basis for the capacity to respond to monoamine-based antidepressants is different from that of susceptibility to major depression. These data provide a proof of concept that major depressive disorder 
is a polygenic disorder, and that the number of risk genotypes may be an indication of susceptibility to the disorder and the severity.

\section{Abbreviations}

VNTR: variable number of tandem repeats

SNP: single nucleotide polymorphism

TRD: treatment resistant depression

DRD4: dopamine receptor D4

ATHF: Antidepressant Treatment History Form

PCR: polymerase chain reaction

DSM: diagnostic and statistical manual

SCID: Structured Questionnaire Interview for DSM-IV-R

\section{Competing interests}

The author(s) declare that they have no competing interests.

\section{Authors' contributions}

HG carried out molecular genetics analyses, data analyses, and drafted the manuscript. FM led in the design, acquisition of support, and coordination of the study. RPE provided mentorship and guidance in the molecular aspects of the protocol. PD contributed the data for the majority of treatment responders, and $\mathrm{MK}, \mathrm{LC}, \mathrm{MB}, \mathrm{WB}$. TS, LM, $\mathrm{MH}$ were principal investigators for the study at their respective sites, contributed recruitment of subjects with TRD, and critically revised the manuscript. All authors read and approved the final manuscript.

\section{Previous presentations}

These data have been presented in abstract form at the Annual Meeting of the American College of Neuropsychopharmacology, December, 2004, the Society of Biological Psychiatry, May, 2005 (poster), and West Coast College of Biological Psychiatry, April, 2006 (talk).

\section{Additional material}

\section{Additional File 1}

TABLE 1S. Primers and method of analysis for all polymorphisms. This is a table in word document format describing all primers, method of analysis and allele descriptions for all polymorphisms discussed in the manuscript. Garriock Supplemental Data lists primer sequences and method of analysis for all polymorphisms described in text in a table in a word document.

Click here for file http://www.biomedcentral.com/content/supplementary/1744-

9081-2-24-S1.doc]

\section{Acknowledgements}

I. Funded in part by National Institute of Mental Health (NIMH) Grant ROIMH066235 to Dr. Moreno, and ROI-MH48977 to Dr. Delgado; Cyberonics Inc., and the Arizona Hispanic Center of Excellence.

2. Treatment resistant depression subjects were a sub-group of the pilot and pivotal studies of vagus nerve stimulation (VNS) therapy for treatmentresistant depression, sponsored by Cyberonics, Inc.; Houston, Tex.

3. Treatment Responders and Healthy controls are a sub-group of subjects who participated in NIMH Tryptophan Depletion Studies mentioned above.

4. The authors thank Susan E. Siefert, ELS, CBC, of Cyberonics, Inc. for her comments on the manuscript.

\section{References}

I. Merikangas KR, Prusoff BA, Weissman MM: Parental concordance for affective disorders: psychopathology in offspring. J Affect Disord 1988, 1 5:279-290.

2. Winokur G, Tsuang MT, Crowe RR: The lowa 500: affective disorder in relatives of manic and depressed patients. Am J Psychiatry 1982, 139:209-212.

3. Gershon ES, Hamovit J, Guroff J], Dibble E, Leckman JF, Sceery W, Targum SD, Nurnberger JIJ, Goldin LR, Bunney WEJ: A family study of schizoaffective, bipolar I, bipolar II, unipolar, and normal control probands. Arch Gen Psychiatry 1982, 39: I I57-II67.

4. Weissman MM, Gershon ES, Kidd KK, Prusoff BA, Leckman JF, Dibble E, Hamovit J, Thompson WD, Pauls DL, Guroff JJ: Psychiatric disorders in the relatives of probands with affective disorders. The Yale University--National Institute of Mental Health Collaborative Study. Arch Gen Psychiatry 1984, 41:13-2I.

5. Kutcher S, Marton P: Affective disorders in first-degree relatives of adolescent onset bipolars, unipolars, and normal controls. J Am Acad Child Adolesc Psychiatry 199I, 30:75-78.

6. Bland RC, Newman SC, Orn H: Recurrent and nonrecurrent depression. A family study. Arch Gen Psychiatry 1986, 43:1085-1089.

7. Warner V, Mufson L, Weissman MM: Offspring at high and low risk for depression and anxiety: mechanisms of psychiatric disorder. J Am Acad Child Adolesc Psychiatry 1995, 34:786-797.

8. Caspi A, Sugden K, Moffitt TE, Taylor A, Craig IW, Harrington H, McClay J, Mill J, Martin J, Braithwaite A, Poulton R: Influence of life stress on depression: moderation by a polymorphism in the 5-HTT gene. Science 2003, 301:386-389.

9. Kendler KS, Kuhn JW, Vittum J, Prescott CA, Riley B: The interaction of stressful life events and a serotonin transporter polymorphism in the prediction of episodes of major depression: a replication. Arch Gen Psychiatry 2005, 62:529-535.

10. Thase ME RAJ: Treatment-Resistant Depression. In Psychopharmacology; The Fourth Generation of Progress Volume 92. 4th edition. Edited by: Bloom FE KDJ. New York, Raven Press; 1995: I08I-1097.

II. Crown WH, Finkelstein S, Berndt ER, Ling D, Poret AW, Rush AJ, Russell JM: The impact of treatment-resistant depression on health care utilization and costs. I Clin Psychiatry 2002, 63:963-971.

12. Baumann P, Broly F, Kosel M, Eap CB: Ultrarapid metabolism of clomipramine in a therapy-resistant depressive patient, as confirmed by CYP2 D6 genotyping. Pharmacopsychiatry 1998, $31: 72$.

13. Association AP: Diagnostic and Statistical Manual of Mental Disorders IV Arlington, VA, American Psychiatric Association; 2000.

14. Oquendo MA, Malone KM, Ellis SP, Sackeim HA, Mann JJ: Inadequacy of antidepressant treatment for patients with major depression who are at risk for suicidal behavior. Am J Psychiatry 1999, 156:190-194. 
15. Prudic J, Sackeim HA, Devanand DP: Medication resistance and clinical response to electroconvulsive therapy. Psychiatry Res 1990, 31:287-296.

16. Prudic J, Haskett RF, Mulsant B, Malone KM, Pettinati HM, Stephens S, Greenberg R, Rifas SL, Sackeim HA: Resistance to antidepressant medications and short-term clinical response to ECT. Am J Psychiatry 1996, 153:985-992.

17. Sackeim HA, Prudic J, Devanand DP, Decina P, Kerr B, Malitz S: The impact of medication resistance and continuation pharmacotherapy on relapse following response to electroconvulsive therapy in major depression. J Clin Psychopharmacol 1990, 10:96-104.

18. Sackeim HA, Rush AJ, George MS, Marangell LB, Husain MM, Nahas Z, Johnson CR, Seidman S, Giller C, Haines S, Simpson RKJ, Goodman RR: Vagus nerve stimulation (VNS) for treatment-resistant depression: efficacy, side effects, and predictors of outcome. Neuropsychopharmacology 200I, 25:713-728.

19. Sackeim HA, Keilp JG, Rush AJ, George MS, Marangell LB, Dormer JS, Burt T, Lisanby SH, Husain M, Cullum CM, Oliver N, Zboyan H: The effects of vagus nerve stimulation on cognitive performance in patients with treatment-resistant depression. Neuropsychiatry Neuropsychol Behav Neurol 200I, I 4:53-62.

20. Sackeim HA, Prudic J, Devanand DP, Nobler MS, Lisanby SH, Peyser S, Fitzsimons L, Moody BJ, Clark J: A prospective, randomized, double-blind comparison of bilateral and right unilateral electroconvulsive therapy at different stimulus intensities. Arch Gen Psychiatry 2000, 57:425-434.

21. George MS, Rush AJ, Marangell LB, Sackeim HA, Brannan SK, Davis SM, Howland R, Kling MA, Moreno F, Rittberg B, Dunner D, Schwartz T, Carpenter L, Burke M, Ninan P, Goodnick P: A one-year comparison of vagus nerve stimulation with treatment as usua for treatment-resistant depression. Biol Psychiatry 2005, 58:364-373.

22. Mazure C, Nelson JC, Price LH: Reliability and validity of the symptoms of major depressive illness. Arch Gen Psychiatry 1986, 43:45I-456.

23. Spitzer RL, Williams JB, Gibbon M, First MB: The Structured Clin ical Interview for DSM-III-R (SCID). I: History, rationale, and description. Arch Gen Psychiatry 1992, 49:624-629.

24. Storey JD, Tibshirani R: Statistical significance for genomewide studies. Proc Natl Acad Sci U S A 2003, 100:9440-9445. hetp://ww.behavioralandbrainfunctions.com/content/2/1/24 